\title{
RENCANA AUDIT TEKNOLOGI INFORMASI MENGGUNAKAN COBIT 2019 PADA UNIT ISTI UNIVERSITAS TELKOM
}

\author{
Ruri Fadhilah ${ }^{1}$, Iqbal Santosa ${ }^{2}$, Lukman Abdurrahman $^{3}$ \\ ${ }^{1}$ Prodi Sistem Informasi, Fakultas Rekayasa Industri, Universitas Telkom \\ ${ }^{2}$ Prodi Sistem Informasi, Fakultas Rekayasa Industri, Universitas Telkom \\ ${ }^{3}$ Prodi Sistem Informasi, Fakultas Rekayasa Industri, Universitas Telkom \\ Email: 1rurifadhilah@student.telkomuniversity.ac.id, ${ }^{2}$ iqbals@ @elkomuniversity.ac.id, \\ 3abdural@telkomuniversity.ac.id
}

(Naskah masuk: 22 Juli 2021, diterima untuk diterbitkan: 16 Agustus 2021)

\begin{abstract}
Abstrak
Teknologi informasi menjadi bagian yang sangat berpengaruh saat ini, baik pada perusahaan, organisasi maupun perguruan tinggi untuk meningkatkan efektivitas dan efisiensi proses bisnis. Universitas Telkom merupakan salah satu perguruan tinggi yang menggunakan teknologi informasi untuk mendukung jalannya operasional proses akademis dan proses bisnis dalam kegiatan sehari-hari serta mengelola dan mengamankan data dari banyak mahasiswa, dosen dan alumni. Direktorat PuTI merupakan salah satu penyedia layanan teknologi informasi yang akan berhubungan dengan seluruh satuan kerja yang ada pada Universitas Telkom. Pengembangan rencana audit teknologi informasi diperlukan untuk mempermudah pelaksanaan audit nantinya. Data yang digunakan untuk penelitian ini bersumber dari dari wawancara, kuesioner dan analisa dokumen internal Direktorat PuTI Universitas Telkom. Analisis dan penilaian pada penelitian ini menggunakan panduan serta kerangka kerja COBIT 2019 dengan metode IT Audit Plan Development Process. Penelitian ini melibatkan kepala bagian serta staff unit infrastruktur dan teknologi informasi Direktorat PuTI Universitas Telkom. Hasil penelitian berupa rekomendasi rencana audit teknologi informasi berdasarkan penilaian risiko yang memiliki dampak tinggi terhadap PuTI Universitas Telkom dan berfokus pada management practice APO11, APO12, BAI08 dan DSS05.
\end{abstract}

Kata kunci: Rencana audit, COBIT 2019, teknologi informasi

\section{INFORMATION TECHNOLOGY AUDIT PLAN USING COBIT 2019 AT TELKOM UNIVERSITY ISTI UNIT}

\begin{abstract}
Information technology has become a very influential part today, both in companies, organizations and universities to improve the effectiveness and efficiency of business processes. Telkom University is one of the universities that uses information technology to support the operational operations of academic processes and business processes in daily activities as well as managing and securing data from many students, lecturers and alumni. The PUTI Directorate is one of the providers of information technology services that will relate to all work units at Telkom University. The development of an information technology audit plan is needed to facilitate the implementation of the audit later. The data used for this study were sourced from interviews, questionnaires and internal document analysis of the Directorate of PUTI, Telkom University. The analysis and assessment in this study uses the COBIT 2019 guidelines and framework with the IT Audit Plan Development Process method. This study involved the head of the department and staff of the IT and infrastructure unit of the PuTI Directorate at Telkom University. The results of the research are recommendations for an information technology audit plan based on a risk assessment that has a high impact on the PuTI of Telkom University and focuses on management practices of APO11, APO12, BAIO8 and DSSO5.
\end{abstract}

Keywords: Audit plan, COBIT 2019, information technology 


\section{PENDAHULUAN}

Teknologi Informasi menjadi peran penting, terutama pada era saat ini untuk setiap organisasi, lembaga atau perusahaan terutama bagi Perguruan Tinggi untuk mendukung jalannya operasional proses akademis dan proses bisnis dalam kegiatan seharihari. Teknologi informasi merupakan kebutuhan yang sangat penting, dalam meningkatkan efektivitas dan efisiensi pada kegiatan pengambilan keputusan, keberjalanan proses bisnis organisasi perusahaan maupun perguruan tinggi [1]. Universitas Telkom menjadi salah satu perguruan tinggi yang telah menggunakan teknologi informasi untuk penunjang bagian pelayanan akademik bagi seluruh civitas akademika. Direktorat Pusat Teknologi Informasi (PuTI) Universitas Telkom merupakan salah satu penyedia layanan teknologi informasi dan akan berkaitan dengan seluruh satuan kerja, termasuk Dosen, Karyawan dan Mahasiswa.

Perencanaan audit ini dibuat dengan menggunakan panduan dari Control Objectives for Information and Related Technology (COBIT) 2019. Karena pada COBIT 2019 sudah dibahas secara lengkap pada 7 komponen yang terdapat pada COBIT 2019, sehingga peneliti dapat merekomendasikan rencana audit yang lengkap. Cobit 2019 memiliki arsitektur yang baru, fleksibel, dinamis dan spesifik mengenai hampir semua topik menggunakan struktur tujuan tata kelola dan manajemen [2]. Panduan serta kerangka kerja tersebut memberikan panduan yang lebih rinci mengenai tata kelola TI perusahaan atau biasa disebut Enterprise Governance of IT (EGIT), menyesuaikan dengan kebutuhan masing-masing perusahaan terdapat 40 inti dari tujuan tata kelola dan tujuan manajemen yang disebut dengan Cobit Core Model [3]. Panduan COBIT 2019 memberikan Tindakan control dan mengoptimalkan nilai pada teknologi informasi yang digunakan perusahaan atau organisasi untuk mencapai tujuan dan mengoptimalkan penggunaan sumberdaya [4].

Audit teknologi informasi (TI) diartikan sebagai proses atau cara yang dibuat secara terstruktur, independen dan objektif serta dilakukan secara berkala sesuai dengan standar untuk memberikan jaminan yang proporsional dan peningkatan yang berkelanjutan untuk keberhasilan penerapan TI [5]. Aktivitas audit dilakukan untuk menilai apakah teknologi informasi dapat menjaga aset dan mengontrol integritas data, untuk secara efektif mengimplementasikan tujuan bisnis, membuat penggunaan sumber daya yang dimiliki organisasi menjadi efisien. Audit teknologi informasi berfokus pada risiko sistem informasi dan tindakan pengendalian dalam organisasi [6].

Rencana audit TI dilakukan untuk meninjau kondisi perusahaan saat ini yang sangat berkaitan dengan kegiatan bisnis. Pengamatan dilakukan dengan mengumpulkan data sebagai bahan analisis risiko untuk menentukan ruang lingkup audit yang akan dilakukan di masa mendatang, dan mengumpulkan informasi untuk mendukung pelaksanaan audit, seperti informasi tentang kegiatan bisnis yang didukung oleh TI, serta prosedur dan peraturan yang terkait dengan kegiatan bisnis tersebut [7]. Langkah pertama dalam merencanakan rencana audit menurut ISACA yaitu, memahami konteks dan strategi perusahaan, menentukan seluruh komponen pada bidang audit TI (Teknologi Informasi), kemudian melakukan penilaian dari seluruh bidang audit TI dan menyimpulkan dan memvalidasi rencana audit TI. Rencana audit dirancang guna untuk mengatasi risiko utama yang akan memberikan pengaruh pada pencapaian tujuan perusahaan, tidak hanya untuk mengatasi risiko pada tujuan unit bisnis saja. Rencana audit TI saat ini, menggunakan seluruh risiko TI sebagai dasar untuk menentukan fokus area audit [8].

Salah satu tugas dari unit Infrastruktur Teknologi Informasi Direktorat Pusat Teknologi Informasi (PuTI) mendukung terlaksananya visi dan misi dari Direktorat PuTI Universitas Telkom yaitu dapat menyediakan sarana dan prasarana layanan teknologi informasi dengan keberfungsian yang kredibel, serta memberikan ide layanan yang menginspirasi untuk mendukung tercapainya Universitas Telkom menjadi perguruan tinggi berkelas dunia dengan cara jalannya fungsi yang ada pada unit tersebut. Direktorat PuTI Universitas Telkom berhasil mempertahankan sertifikasi ISO (International Organization for Standarzation) 20000. Untuk dapat mempertahankan sertifikasi tersebut, dan mencapai sertifikasi ISO 27000 guna mengelola dan mengamankan data dari banyak mahasiswa, alumni dan dosen.

Berdasarkan latar belakang berikut, Pada Direktorat PuTI Universitas Telkom belum adanya rencana audit yang spesifik. Maka, perlu dibuatnya rencana audit TI sebelum dilakukan audit secara rutin yang bertujuan untuk memastikan layanan tersebut sudah mencapai minimum yang dijaminkan dan menyediakan layanan dengan keberfungsian yang handal serta untuk mengukur dan mencapai sertifikasi tersebut. Audit pada teknologi informasi di sebuah perusahaan atau organisasi melakukan pengecekan dalam pelaksanaan kontrol, kemudian adanya kegiatan analisis dan mendapatkan temuan bukti untuk diberikan rekomendasi kembali dalam permasalahan yang ditemukan [9].

Tujuan dari penelitian ini untuk memahami konteks dan strategi, memahami komponen pada bidang audit teknologi informasi Direktorat PuTI Universitas Telkom, mengetahui hasil penilaian risiko pada bidang audit teknologi informasi di Unit Infrastruktur Teknologi Informasi (IsTI) Direktorat PuTI Universitas Telkom dan menghasilkan rekomendasi rencana audit teknologi informasi sesuai dengan COBIT 2019. 
Pengembangan rencana audit teknologi informasi pada unit IsTI Universitas Telkom ini belum pernah dilakukan penelitian sebelumnya. Akan tetapi, terdapat beberapa penelitian yang dapat dijadikan sebagai acuan untuk penelitian ini, seperti penelitian yang berjudul "Audit Kesesuaian Rencana Strategis TI Perguruan Tinggi Terhadap Prinsip Good University Governance (GUG)" tahun 2018. Penelitian ini menjelaskan penerapan tata kelola teknologi informasi pada Politeknik Negri Bali (PNB) dan penerapan Good University Governance (GUG) dengan tujuan untuk mengoptimalkan manfaat khususnya pada aspek penyelarasan antara teknologi informasi dan strategi bisnis, serta mengukur tingkat implementasi prinsip GUG (akuntabilitas, transparansi, nirlaba, penjaminan mutu dan efektifitas \& efisiensi) dan memperoleh ukuran tingkat kapabilitas proses TI di Politeknik Negeri Bali. Penelitian ini menggunakan kerangka kerja dari COBIT 5.0 dengan focus pada 10 proses yaitu EDM01, EDM02, APO01, APO02, APO03, APO05, APO07, APO08, BAI01, BAI02. Hasil penelitian ini yaitu, Pada level 1 rekomendasi prioritas adalah rekomendasi untuk APO 05.03 untuk melakukan evaluasi dan pemilihan program yang akan didanai. Pada level 2 rekomendasi prioritasnya adalah level 2.2.2 yang bertujuan untuk menentukan kebutuhan dari dokumentasi dan control pada tiap proses. Pada level 3 rekomendasi prioritas adalah rekomendasi level 3.2.3 yang bertujuan untuk memastikan kompetensi yang diperlukan. Terakhir yaitu level 4, rekomendasi yang menjadi paling prioritas disini adalah rekomendasi level 4.2.4 yang bertujuan untuk mengidentifikasi dan menerapkan perbaikan [15].

Selanjutnya, penelitian yang berjudul "Audit Tata Kelola Teknologi Informasi Menggunakan Framework COBIT 5 (Studi Kasus: Skatsa Data Integra)" tahun 2020. Penelitian ini menjelaskan kesesuaian dalam penerapan TI pada perusahaan, dilakukan audit tata kelola pada Skatsa Data Integra (SDI). Penelitian ini menggunakan kerangka kerja COBIT 5 yang dapat membantu penyelarasan TI dengan tujuan bisnis perusahaan. Penilaian akan dilakukan pada domain APO01 dengan capability level 1, APO07 dengan capability level 0, dan MEA01 dengan capability level 0 . Hasil penelitian ini yaitu, APO01, APO07, dan MEA01 belum dapat mencapai target capability level [14].

\section{METODE PENELITIAN}

Metode Penelitian rencana audit teknologi informasi pada unit IsTI Universitas Telkom dengan framework COBIT 2019 IT Audit Plan Development Process diilustrasikan pada Gambar 1.

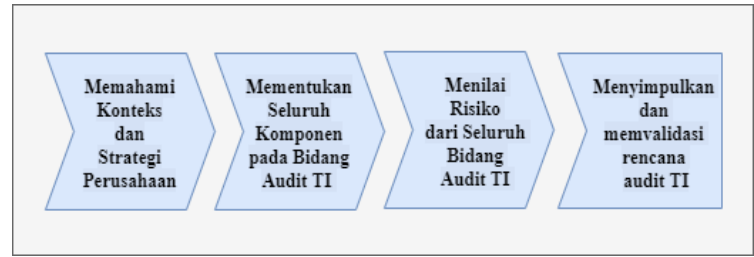

Gambar 1. Metode Penelitian

Langkah pertama diawali dengan memahami strategi perusahaan, kemudian memahami tujuan perusahaan, setelah memahami tujuan dari perusahaan perlu juga memperdalam pemahaman mengenai profil risiko yang ada pada perusahaan dan memahami masalah saat ini, terkait dengan teknologi informasi. Selanjutnya, menentukan dan mempertimbangkan seluruh komponen pada bidang audit teknologi informasi serta mempertimbangkan komponen dari sistem tata kelola, kemudian menentukan portofolio audit teknologi informasi dan menentukan seluruh bagian audit teknologi informasi. Setelah menentukan komponen pada seluruh bidang audit TI selanjutnya mempertimbangkan faktor desain COBIT 2019 sebagai faktor risiko. Langkah akhir yaitu melakukan validasi dan menyimpulkan rencana audit, selanjutnnya menyelesaikan konflik utama terkait perusahaan serta, perusahaan dapat mempublikasikan rencana audit IT yang sudah di validasi.

Pengumpulan data untuk penelitian ini menggunakan data primer dan sekunder. Teknik pengumpulan data yang menunjang penelitian ini bersumber dari wawancara dengan pemangku kepentingan terkait, Analsis dokumen internal perusahaan yang relenvan dengan penelitian, memberikan kuesioner kepada narasumber terkait.

\section{HASIL DAN PEMBAHASAN}

\subsection{Memahami Konteks dan Strategi Perusahaan}

\subsubsection{Memahami Strategi Perusahaan}

Memahami strategi perusahaan merupakan langkah awal dari pembuatan rekomendasi rencana audit. Pada Gambar 2 terlihat strategi perusahaan mana yang dapat menjadi strategi pendukung dan strategi utama dari PuTI Universitas Telkom. Strategi utama yaitu berfokus pada inovation/differentiation sedangkan strategi pendukung yaitu growth/acquisiton, client service/stability dan cost leadership. Perusahaan dapat memiliki strategi yang berbeda, yang dapat dinyatakan sebagai satu atau lebih arketipe. Organisasi biasanya memiliki strategi utama dan paling banyak dan satu strategi sekunder [12]. 


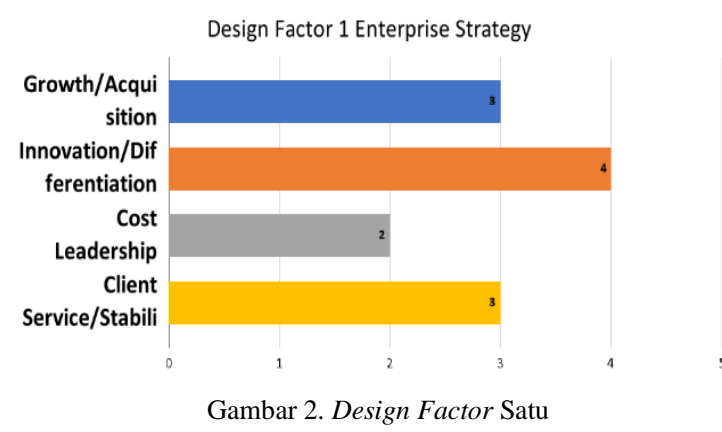

\subsubsection{Memahami Tujuan Perusahaan}

Selanjutnya, tahap memahami tujuan perusahaan guna untuk mengetahui fokus utama agar perusahaan dapat mencapai tujuan yang diinginkan. Pada Gambar 3 terlihat bahwa ada 3 fokus utama dengan nilai lima. Tiga fokus utama itu ialah EG1 yaitu portfolio of competitive products and services, EG4 yaitu quality of financial information dan EG10 yaitu staff skills, motivation and productivity.

\section{Design Factor 2 Enterprise Goals (Input)}

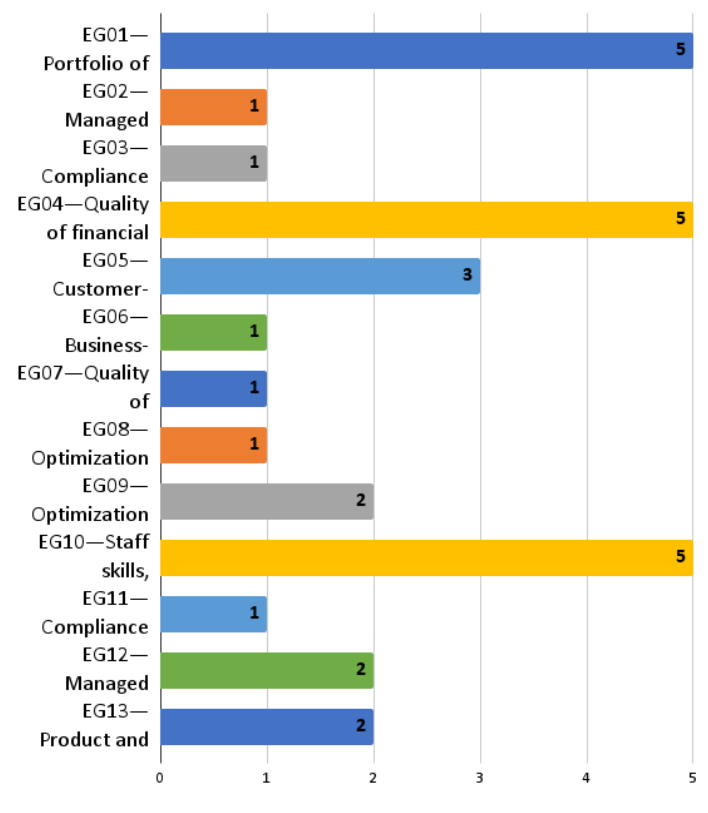

Gambar 3. Design Factor Dua

\subsubsection{Memahami Profil Risiko}

Tahap ini melakukan identifikasi risiko TI, dengan mengetahui risiko TI yang dihadapi perusahaan saat ini dan melakukan kategorisasi pada risiko TI tersebut. Pada Gambar 4 berikut merupakan hasil dari identifikasi risiko TI yang menunjukkan area mana yang memiliki risiko paling tinggi dan menjadi fokus utama yang harus diperhitungkan kembali, fokus utamanya yaitu IT cost \& oversight dan Data \& information management .

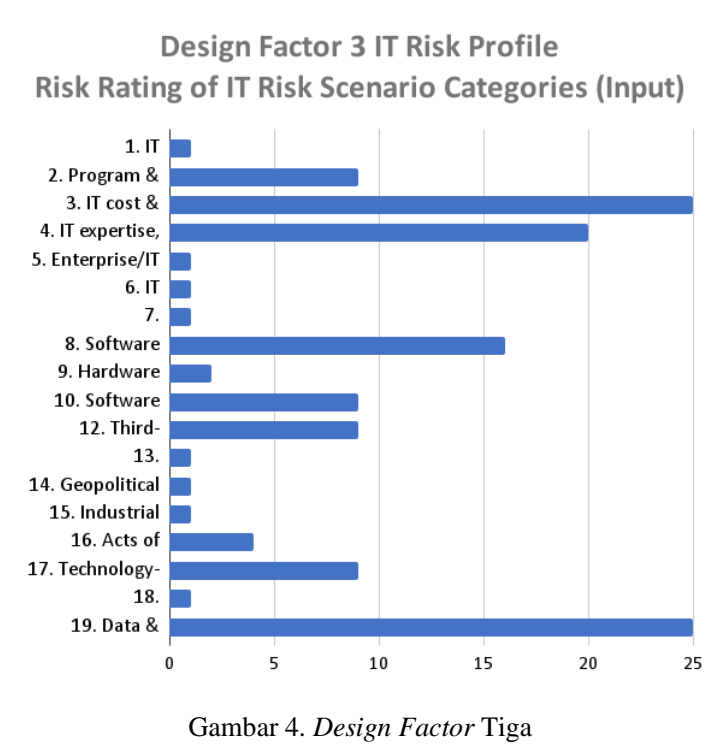

\subsubsection{Memahami Isu-isu Terkait TI saat ini}

Tahap ini mengkategorisasikan masalah yang dihadapi oleh perusahaan. Gambar 5 menunjukkan bahwa Direktorat PuTI Universitas Telkom harus berfokus pada masalah TI yaitu kesulitan dalam berinovasi menggunakan teknologi informasi. Dengan itu, masalah tersebut akan dievaluasi kembali menggunakan metode penilaian risiko TI dan dikelompokkan, serta diidentifikasi area mana yang paling mempengaruhi masalah tersebut.

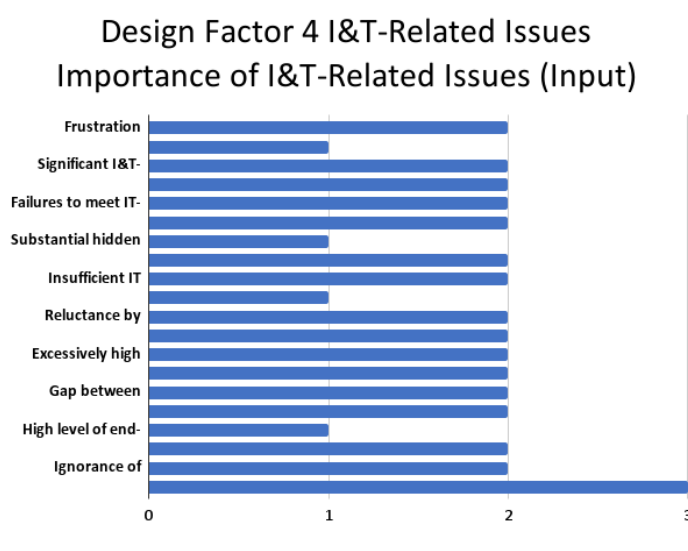

\subsection{Menentukan Seluruh Komponen Bidang Audit TI}

Setelah memahami strategi, tujuan, profil risiko dan masalah yang terjadi perusahaan, berikut merupakan focus area management objective dan skor dari analisis penilaian sebelumnya. Pada Tabel 1 menjelaskan focus utama dari unit Infrastruktur Teknologi Informasi (IsTI) pada Direktorat PuTI Universitas Telkom. 
Tabel 1. Fokus Utama pada Unit Infrastruktur TI

\begin{tabular}{|c|c|c|c|}
\hline No & $\begin{array}{l}\text { Management } \\
\text { Objectives }\end{array}$ & $\begin{array}{l}\text { Score Step 2: } \\
\text { Determine the } \\
\text { initial scope of } \\
\text { the } \\
\text { Governance } \\
\text { System }\end{array}$ & $\begin{array}{l}\text { Score Step 3: } \\
\text { Refine the } \\
\text { scope of the } \\
\text { Governance } \\
\text { System }\end{array}$ \\
\hline 1. & $\begin{array}{l}\text { APO11-Managed } \\
\text { Quality }\end{array}$ & 90 & 80 \\
\hline 2. & $\begin{array}{l}\text { APO12-Managed } \\
\text { Risk }\end{array}$ & -55 & 45 \\
\hline 3. & $\begin{array}{l}\text { BAI08-Managed } \\
\text { Knowledge }\end{array}$ & 85 & 80 \\
\hline 4. & $\begin{array}{l}\text { DSS05-Managed } \\
\text { Security Services }\end{array}$ & -45 & 50 \\
\hline
\end{tabular}

\subsection{Menilai Risiko dan Seluruh Bidang Audit TI}

Pada Tabel 2 berikut menunjukkan manajemen objektif mana yang dijadikan subjek audit pada unit IsTI sesuai dengan hasil skor pada assessment sebelumnya.

Tabel 2. Fokus Utama pada Unit Infrastruktur TI

\begin{tabular}{cc}
\hline Unit Bisnis & \multicolumn{1}{c}{ Audit Subject } \\
\hline IsTI & APO11-Managed Quality \\
IsTI & APO12-Managed Risk \\
IsTI & BAI08-Managed Knowledge \\
IsTI & $\begin{array}{l}\text { DSS05-Managed Security } \\
\text { Services }\end{array}$ \\
\hline
\end{tabular}

Setelah dilakukan identifikasi subjek apa yg akan di audit, selanjutnya menilai risiko bisnis dan risiko TI yang ada pada unit IsTI dan sesuai dengan subjek audit. Kategori risiko dinilai berdasarkan kemungkinan yang terjadi dan dampak terhadap Unit IsTI Direktorat PuTI Universitas Telkom, jika risiko tersebut tidak dikelola dengan baik, dapat memberikan kerugian yang signifikan. Pada Tabel 3 merupakan pengukuran keterjadian risiko dan Tabel 4 pengukuran untuk dampak risiko.

Tabel 3. Level Kemungkinan

\begin{tabular}{|c|c|}
\hline $\begin{array}{c}\text { Level } \\
\text { Kemungkinan } \\
(\text { Likelihood }) \\
\end{array}$ & Kriteria \\
\hline $\begin{array}{c}\text { (Hampir Tidak } \\
\text { Terjadi) }\end{array}$ & 1 kejadian dalam 1 semester \\
\hline 2 (Jarang Terjadi) & $\begin{array}{c}>1 \text { sampai } 3 \text { kejadian dalam } 1 \\
\text { semester }\end{array}$ \\
\hline 3 (Kadang Terjadi) & $\begin{array}{c}\text { >3 sampai } 5 \text { kejadian dalam } 1 \\
\text { semester }\end{array}$ \\
\hline 4 (Sering Terjadi) & $\begin{array}{c}\text { >5 sampai } 10 \text { kejadian dalam } 1 \\
\text { semester }\end{array}$ \\
\hline
\end{tabular}

Tabel 4. Level Dampak

\begin{tabular}{cl}
\hline $\begin{array}{c}\text { Level Dampak } \\
\text { (Consequence) }\end{array}$ & \multicolumn{1}{c}{$\begin{array}{c}\text { Kriteria Dampak/Konsekuensi/ } \\
\text { Keparahan (Generik) }\end{array}$} \\
\hline 1 Tidak Signifikan & $\begin{array}{l}\text { Terjadi dampak kecil berupa kerugian } \\
\text { non finansial pada area dampak risiko } \\
\text { dimana kejadian masih dapat di tangani } \\
\text { melalui prosedur dan proses kerja yang } \\
\text { berlaku. }\end{array}$ \\
& $\begin{array}{l}\text { Terjadi dampak kecil pada area dampak } \\
\text { risiko dimana kejadian masih dapat di } \\
\text { tangani melalui prosedur dan proses } \\
\text { 2 Minor }\end{array}$ \\
& $\begin{array}{l}\text { Terja yang berlaku. } \\
\text { area dampak risiko tetapi dapat } \\
\text { ditangani melalui prosedur dan proses } \\
\text { kerja yang berlaku. }\end{array}$ \\
& $\begin{array}{l}\text { Terjadi dampak signifikan dan } \\
\text { berpotensi sistemik pada area dampak } \\
\text { risiko yang perlu ditangani secara cepat } \\
\text { dan tepat. }\end{array}$ \\
4 Signifikan & $\begin{array}{l}\text { Terjadi dampak membahayakan dan } \\
\text { sistemik pada area dampak risiko yang } \\
\text { perlu ditangani secara cepat dan tepat. }\end{array}$ \\
\hline 5ignifikan & \\
\hline
\end{tabular}

Berikut Tabel 5 untuk menentukan rentang peringkat risiko tinggi (High), sedang (Medium) atau rendah (Low).

Tabel 5. Rentang Level Risiko

\begin{tabular}{ccc}
\hline Level & $\begin{array}{c}\text { Rentang Skor Risiko } \\
\text { Gabungan }\end{array}$ & $\begin{array}{c}\text { Siklus Tahunan yang } \\
\text { Direkomendasikan }\end{array}$ \\
\hline $\mathrm{H}$ & $117-175$ & Setiap 1 hingga 2 tahun \\
$\mathrm{M}$ & $59-116$ & Setiap 2 hingga 3 tahun \\
$\mathrm{L}$ & $1-58$ & Setiap 3 hingga 5 tahun \\
\hline
\end{tabular}

Sebagai bagian dari langkah dalam penilaian risiko, selanjutnya perlu menentukan subjek audit yang direkomendasikan untuk dilakukannya audit secara berkala. Dengan dilakukannya pemeriksaan subjek audit secara berkala ini untuk memastikan bahwa area yang memiliki risiko tinggi sering ditinjau dan area yang memiliki risiko rendah ditinjau dalam rentang lima tahun. Tabel 6 menunjukkan penilaian risiko pada masing-masing area audit subjek.

Tabel 6. Skor dan Level Penilaian Risiko

\begin{tabular}{lcc}
\hline \multicolumn{1}{c}{ Audit Subject } & Skor & Level \\
\hline APO11-Managed Quality & 40 & $\mathrm{~L}$ \\
APO12-Managed Risk & 22 & $\mathrm{~L}$ \\
BAI08-Managed Knowledge & 30 & $\mathrm{~L}$ \\
DSS05-Managed Security Services & 66 & $\mathrm{M}$ \\
\hline
\end{tabular}




\subsection{Menyimpulkan dan Memvalidasi Rencana Audit}

Setelah melakukan penilaian risiko berdasarkan risiko yang terjadi pada unit Infrastruktur teknologi informasi (IsTI) pada PuTI Universitas Telkom dan dikategorikan sesuai dengan management practice COBIT 2019, Berikut Tabel 7 merupakan hasil ringkasan yang didalamnya terdapat level risiko dan alokasi hari audit.

Tabel 7. Level dan Alokasi Hari Audit

\begin{tabular}{lcc}
\hline \multicolumn{1}{c}{ Audit Subject } & $\begin{array}{c}\text { Level } \\
\text { Risiko }\end{array}$ & $\begin{array}{c}\text { Hari Audit } \\
\text { Dialokasikan }\end{array}$ \\
\hline $\begin{array}{l}\text { APO11-Managed } \\
\text { Quality } \\
\text { APO12-Managed }\end{array}$ & $\mathrm{L}$ & 3 Hari \\
$\begin{array}{l}\text { Risk } \\
\text { BAI08-Managed }\end{array}$ & $\mathrm{L}$ & 1 Hari \\
Knowledge & $\mathrm{L}$ & 3 Hari \\
$\begin{array}{l}\text { DSS05-Managed } \\
\text { Security Services }\end{array}$ & $\mathrm{M}$ & 1 Hari \\
\hline
\end{tabular}

Rekomendasi hari untuk audit ditentukan berdasarkan unit yang terlibat. Untuk subjek audit yang dialokasikan selama 1 hari yaitu APO12Manage Risk dan DSS05-Manage Security Service, karena pelaksanaan audit nanti akan dilakukan hanya pada unit Infrastruktur teknologi informasi saja, dengan itu dari hasil penilaian sebelumnya unit IsTI perlu berfokus dalam mengelola risiko dan pengelolaan keamanan pada layanan. Kemudian untuk subjek audit yang direkomendasikan selama 3 hari yaitu APO11-Manage Quality dan BAI08Manage Knowledge, nantinya akan dilakukan audit pada semua unit yang ada pada PuTI Universitas Telkom yaitu unit pengembangan produk TI (DevTI), unit infrastruktur TI (IsTI) dan unit riset dan layanan teknologi informasi (RiYanti).

\section{KESIMPULAN}

Kesimpulan yang dapat diambil berdasarkan analisis yang telah dilakukan dalam pengembangan rencana audit teknologi informasi ini, yaitu pada strategi utama Direktorat PuTI Universitas Telkom berfokus pada inovation/differentiation. Fokus utama dari tujuan PuTI setelah dilakukan analisis berfokus pada Enterprise goals (EG) satu yaitu portfolio of competitive products and services, EG4 quality of financial information dan EG10 staff skills, motivation and productivity. Pada analisis identifikasi risiko TI, PuTI berfokus pada IT cost \& oversight dan Data \& information management. Masalah yang dihadapai PuTI ialah kesulitan dalam berinovasi menggunakan teknologi informasi.

Hasil analisis penilaian menunjukkan management practice BAI05-manage organizational change, yang perlu dilakukan perbaikan oleh
Direktorat PuTI Universitas Telkom, serta untuk unit Infrastruktur TI berfokus pada APO11-Manage Quality, APO12-Manage Risk, BAI08-Manage Knowledge dan DSS05-Manage Security Service, berdasarkan skor tertinggi hasil assessment design toolkit COBIT 2019 dan relevan dengan unit Infrastruktur TI.

Risiko yang didapat dari fokus utama management practice unit IsTI untuk dilakukan perbaikan lebih lanjut pada APO11 memiliki skor 40 dengan level rendah (low), APO12 dengan skor 22, level rendah dan BAI08 dengan skor 30 dengan level rendah, sedangkan DSS05 memiliki skor 66 dengan level sedang (medium).

Hasil dari analisis penelitian tugas akhir yang telah dilakukan, peneliti memberikan rekomendasi rencana audit teknologi informasi berdasarkan COBIT 2019, yang dimana didalamnya terdapat lingkup audit, metode audit, sumber daya yang dibutuhkan, jadwal pemeriksaan, yang dapat diterapkan pada unit Infrastruktut TI Direktorat Pusat Teknologi Informasi (PuTI) Universitas Telkom dengan menyesuaikan dari kebutuhan bisnis maupun kebutuhan TI organisasi.

\section{DAFTAR PUSTAKA}

[1] Hardinata dan R. Septian. 2019. "Audit Tata Kelola Teknologi Informasi menggunakan Cobit 5 (Studi Kasus: Universitas Pembangunan Panca Budi Medan)", Jurnal Teknik dan Informatika, vol. 6 no. 1, pp. 1-4

[2] Sarifah, Bakiatus, Rokhman Fauzi, and I. Santosa. 2020. "Analisis Dan Perancangan Proses Manajemen Kontrol Internal Ti Menggunakan Kerangka Kerja Cobit 2019 Di Pt Inti (persero)", eProceedings of Engineering 7.2, vol. 7, no. 2, pp. 1-7

[3] D. Steuperaert., 2019. "COBIT 2019: A significant update." EDPACS 59.1, pp. 1-6. Doi: 10.1080/07366981.2019.1578474

[4] S. F. Bayastura., S. Krisdina., \& A. P. Widodo, A 2021. "ANALISIS TATA KELOLA TEKNOLOGI INFORMASI MENGGUNAKAN FRAMEWORK COBIT 2019 PADA PT. XYZ'. JIKO (Jurnal Informatika dan Komputer), vol.4, no.1, pp. 6875. Doi: 10.33387/jiko

[5] B. R. Aditya, R. Ferdiana and P. I. Santosa. 2018 "Toward Modern IT Audit- Current Issues and Literature Review", 4th International Conference on Science and Technology (ICST), pp. 1-6. Doi: 10.1109/ICSTC.2018.8528627.

[6] L. Tingliao. 2016 "The IT audit research based on the information system success model and COBIT", 2016 10th International Conference on Intelligent Systems and Control (ISCO), pp. 1-3. doi: 10.1109/ISCO.2016.7727117 .

[7] R. Budiraharjo. 2016. "Audit Pemanfaatan Teknologi Informasi Institusi Pendidikan Tinggi Menggunakan COBIT 5 Framework 
(Studi Kasus: ITENAS Bandung)", vol. 1, no.1, pp. $462-466$

[8] B. R. Aditya., R. Ferdiana,, \& Kusumawardani, S. S. 2018. "Requirement and Potential for Modernizing IT Risk Universe in IT Audit Plan", 2018 2nd International Conference on Informatics and Computational Sciences (ICICoS), pp. 1-5. Doi:10.1109/ICICOS.2018.8621808.

[9] R. E. Rodriguez-Rodriguez, A. F. Quevedo Vega, A. F. Sanchez, A. López and J. Fernando. 2018. "Design of an Automation Model for Taking Documentary Evidence of Compliance Tests of the IT Audit", Congreso Internacional de Innovación y Tendencias en Ingeniería (CONIITI), pp. 1-5. Doi: 10.1109/CONIITI.2018.8587090.

[10] K. Rehage, S. Hunt, and F. Nikitin. 2008 "Developing the IT Audit Plan", Global Technology Guide (GTAG), pp. 1 - 34 .

[11] ISACA. 2018. "Developing the IT Audit Plan Using COBIT 2019”, ISACA Journal, pp. 1115.

[12] ISACA. 2018. "Introduction and Methodology", ISACA Journal, pp. 23.

[13] ISACA. 2018. "Designing an Information and Technology Governance Solution", ISACA Journal, pp. 21-28.

[14] D. C. U. Lieharyani., 2018. "Audit Kesesuaian Rencana Strategis TI Perguruan Tinggi Terhadap Prinsip Good University Governance (GUG) (Studi Pada Politeknik Negeri Bali)" (Doctoral dissertation, Institut Teknologi Sepuluh Nopember), pp. 1-154.

[15] E. A. Wijaya., E. Darwiyanto., \& G. . Wisudiawan. 2020. "Audit Tata Kelola Teknologi Informasi Menggunakan Framework Cobit 5 (studi Kasus: Skatsa Data Integra)”, pp. $1-14$. 